\title{
PENGEMBANGAN WEB ALUMNI DENGAN MENGGUNAKAN LINKEDIN PADA PERGURUAN TINGGI
}

\author{
Aris Martono ${ }^{1}$ \\ Giandari Maulani ${ }^{2}$ \\ Siti Pujianingsih ${ }^{3}$ \\ Dosen STMIK Raharja ${ }^{1,2}$, STMIK Raharja Jurusan Sistem Informasi, ${ }^{3}$ \\ Jl. Jendral Sudirman No. 40, Modern Cikokol, Tangerang ${ }^{1,2,3}$ \\ Email: aris.martono@raharja.info ${ }^{1)}$ giandari@raharja.info ${ }^{2)}$ pujianingsih@raharja.info ${ }^{3)}$
}

\begin{abstract}
ABSTRAK
Tujuan penelitian ini adalah memanfaatkan media sosial linkedin untuk membuat jaringan alumni dan informasi lowongan kerja dimana aktivasi ke jaringan ini sebagai prasyarat untuk mengambil ijazah sehingga hal ini menumbuhkan ikatan emosional antar alumni dan perguruan tinggi. Metode penelitian yang digunakan adalah metode survei dengan melakukan observasi dan wawancara disertai studi pustaka. Kemudian dilakukan analisis system untuk mengetahui kelemahan sistem dan kebutuhan informasi bagi penggunanya. Hasil dari analisis ini adalah setiap mahasiswa dapat melakukan aktivasi pada web alumni untuk persyaratan mengambil ijazah, menjalin komunikasi sesama alumni, mahasiswa dan dosen serta notifikasi email masuk ke setiap anggota mengenai lowongan pekerjaan. Sedangkan kelemahannya adalah media social ini baru dan hanya masyarakat professional saja yang tahu. Implementasi system ini berupa web alumni yang menyediakan fasilitasfasilitas seperti regenerate linkedin access token, mencari nama-nama alumni, profil alumni, menu pekerjaan yang disediakan perusahaan dan profilnya serta lamaran kerja yang disertakan pada setiap profil alumni. Adanya web alumni dengan menggunakan linkedin ini, setiap alumni dapat memperolah informasi lowongan pekerjaan perusahaan dan profilnya serta dapat komunikasi antar alumni dan perguruan tinggi.
\end{abstract}

Kata Kunci: media sosial, jaringan alumni, linkedin

\begin{abstract}
The purpose of this study is to utilize social media to create a network of alumni linkedin and job information to the network in which the activation of this as a prerequisite for taking the diploma so that it fosters an emotional bond between alumni and the university. The method used is surveymethod with observation and interviews with literature. Then analysis system to identify the weaknesses in the system and the information needs of its users. The results of this analysis is that every student can perform activation on the alumni web to take a diploma requirements, establish communication among alumni, students and faculty as well as notifications of incoming mail to each member on job vacancies. The disadvantage is social media is new and only professional people who know. Implementation of this system in the form of web alumni who provide facilities such as linkedin regenerate the access token, looking for names of alumni, the alumni profile, menu provided by the company and job profile and job application that is included in each profile alumni. The existence of the alumni web by using this linkedin, each alumnus can obtain job information and company profile and can communication between alumni and the university.
\end{abstract}

Keywords: social media, the alumni network, linkedin 


\section{PENDAHULUAN}

Di zaman modern ini sudah banyak perkembangan di bidang pendidikan dan teknologi informasi, sehingga banyak sekali penemuan-penemuan yang dilakukan oleh para ahli dalam mengembangkan suatu ilmu yang berguna terutama di bidang teknologi dan informasi (IT). Semakin canggih suatu teknologi yang di berikan maka semakin banyak informasi yang didapatkan, dengan adanya teknologi yang bagus sudah dapat dipastikan informasi yang akan di berikan dapat di sharing ke suluruh dunia. Contohnya seperti jejaring sosial ini sangat berpengaruh pada masyarakat di seluruh dunia, begitupun yang berhubungan dengan pendidikan kenapa demikian? karena teknologi berpengaruh besar terhadap dunia pendidikan contohrrnya seorang mahasiswa yang mendapatkan tugas pasti mereka dengan mudah mencari jawabannya pada media sosial seperti google. Sesungguh nya dengan perkembangan teknologi dan jejaring sosial ini dapat di manfaatkan dengan cara membuat sebuah wadah berkumpulnya satu kesatuan antara mahasiswa, dosen dan para alumninya.

Akan lebih baik jika suatu unversitas maupun perguruan tinggi menghimpun secara keseluruhan mahasiswa, dosen dan alumninya di suatu jejaring sosial karena dengan adanya wadah yang dapat menghimpun semuanya maka tidak menutup kemungkinan akan tetap terjaga komunikasi. Sehingga apabila mahasiswa yang sudah lulus (alumni) tidak begitu saja pergi meninggalkan universitas maupun perguruan tinggi, mereka masih dapat bisa berkomunikasi dan mengetahui informasi yang ada pada unversitas da perguruan tinggi dan sebaliknya universitas dan perguruan tinggi pun akan mengetahui aktivitas dan pekerjaan yang dilakukan alumninya. Sudah banyak universitas dan perguruan tinggi yang sudah mempunyai jejaring sosial yang menjadi wadah para alumninya agar bisa bergabung di dalamnya contoh nya adalah web alumni, akan lebih baik jika web alumni tidak hanya dimanfaatkan sebagai komunikasi saja antar alumni dan kampusnya melainkan akan lebih baik jika web alumni dimanfaatkan untuk membantu para alumni memberikan informasi mengenai lowongan pekerjaan. Tidak sedikit lulusan dari universitas maupun perguruan tinggi yang sulit untuk mencari pekerjaan apabila ini semua terdapat didalam web alumni yang dimiliki kampus akan sangat bermanfaat sekali.

Studi kasus ini dilakukan di lingkungan Perguruan Tinggi Raharja merupakan lembaga pendidikan IT (Informasi Technology) sudah mempunyai web alumni dijejaring sosial LinkedIn di manfaatkan untuk para alumni, mahasiswa, dan dosen agar bisa berkomunikasi satu dengan yang lain dan didalam LinkedIn juga terdapat informasi mengenai lowongan pekerjaan yang akan didapatkan oleh para alumni dan mahasiswa nya melalui email selain itu para alumni dapat saling memberikan informasi untuk membantu memberikan info mengenai pekerjaan untuk alumni yang lain dalam mendapatkan pekerjaan.

LinkedIn adalah jejaring sosial profesional yang didirikan pada desember 2002 akan diluncurkan pada tanggal 5 Mei 2003, sangat bermanfaat bagi yang mempunyai account dan yang telah mendaftar pada linkedin karena pada linkedin ini sangat membantu sekali dalam mencari informasi tentang lowongan pekerjaan. Pada perguruan tinggi raharja mempunyai Ten Pilar Information (TPI) dalam mendukung perkuliahan sehingga email yang digunakan untuk mendaftarkan account pada linkedin harus menggunakan email rinfo agar terhubung dengan sistem yang ada pada perguruan tinggi raharja. Dan pada hari ini dengan adanya linkedin, perguruan tinggi raharja sangat memanfaatkan fungsi dari adanya linkedin ini dibuktikan dengan para alumni yang wajib mempunyai akun linkedin agar dapat melakukan activate linkedin pada web alumni yang dimiliki oleh perguruan tinggi raharja. Dengan adanya activate linkedin pada web alumni dapat membuktikan bahwa alumni ini benar-benar alumni yang berasal dari perguruan tinggi raharja tangerang membuktikan dengan membawa ijazah. 
Para alumni dan mahasiswa yang mengetahui akun linkedin pada Perguruan Tinggi Raharja masih sangat minim karena masih banyak alumni dan mahasiswa yang belum mengetahui penting nya memiliki akun linkedin dan ketidaktahuan mahasiswa dan alumni terhadap linkedin. Terutama untuk alumni yang baru lulus dimana sudah terdapat surat keputusan dari manajemen bahwa alumni yang baru lulus harus melakukan activate pada web alumni, dengan melakukan activate alumni harus terlebih dahulu mempunyai akun linkedin.

Setiap manusia memiliki gagasan, pemikiran dan pemahaman yang berbeda-beda dan untuk menghindari kekliruan atau kesalahpahaman dan sekaligus untuk membantu dalam memahami penelitian ini maka dibatasi dengan ruang-lingkup kegiatan yaitu:

1. Melakukan observasi pada sistem informasi linkedin ini untuk mengetahui seberapa banyak mahasiswa di Perguruan Tinggi Raharja yang mengetahui linkedin.

2. Mendeskripsikan bagaimana cara mahasiswa agar dapat tertarik untuk membantu membuat account pada jejaring sosial linkedin.

3. Memfokuskan pada analisa sistem informasi di jejaring sosial linkedin pada account Perguruan Tinggi Raharja.

Dengan adanya jejaring sosial Linkedin di Perguruan Tinggi Raharja akan terbantu dalam mengetahui para mahasiswa dan alumninya yang sudah mempunyai pekerjaan dan berapa banyak yang telah bergabung di akun yang mempunyai pekerjaan di bidang tertentu. Sedangkan manfaat bagi para mahasiswa dimudahkan untuk mengetahui jejaring sosial para profesional dan membantu dalam mendapatkan pekerjaan dengan cepat.

\section{METODE PENELITIAN}

Penelitian ini menggunakan metode survey dan metode analisis sistem. Metode survey meliputi metode observasi, metode wawancara dan metode studi pustaka. Metode observasi merupakan metode yang dilakukan oleh penulis secara langsung pada perguruan tinggi raharja. Metode ini dilakukan untuk mengumpulkan data dimana sumber informasi sangat penting dalam membantu menganalisis sistem nanti. Metode wawancara yang dilakukan langsung kepada mahasiswa untuk mengetahui seberapa banyak mahasiswa untuk mengetahui dan mempunyai account linkedin. Metode ini dilakukan untuk mencari data mengenai kekurangan dari sistem jejaring sosial linkedin yang telah berjalan. Metode studi pustaka yaitu untuk mencari referensi-referensi yang terdapat pada buku-buku, karya ilmmiah, internet dan laporan ilmiah yang berhubungan dengan penelitian yang dilakukan.

Metode analisis sistem yaitu untuk mengetahui kelemahan sistem dan kebutuhan informasi bagi penggunanya. Menganalisis kelemahan sistem yang lama dimaksudkan untuk menemukan penyebab permasalahan-permasalahan yang terjadi dan mengakibatkan system yang lama kurang berfungsi. Permasalahan-permasalahan pada sistem yang lama perlu ditemukan dan diperbaiki menjadi system yang lebih baik. Perbaikan-perbaikan pada system yang lama berupa perbaikan dalam bentuk informasi yang disediakan oleh system yang akan dikembangkan atau dibuat. Informasi-infomasi ini harus sesuai dengan kebutuhan penggunanya dan relevan pada saat dibutuhkan. [4]

\section{KAJIAN LITERATUR}

Sistem informasi adalah suatu sistem didalam organisasi yang mempertemukan kebutuhan pengolahan transaksi harian, mendukung operasi, bersifat manajerial dan kegiatan strategi serta menyediakan pihak luar tertentu dengan laporan-laporan yang diperlukan. Sistem informasi merupakan kombinasiteratur dari orang-orang, hadware, 
software, jaringan komunikasi, dan sumber daya data untuk mengumpulkan serta menyebarkan informasi dalam organisasi.[10]

Sistem informasi merupakan suatu kegiatan untuk mengumpulkan, memproses, menyimpan, menganalisis, dan menyebarkan informasi untuk tujuan tertentu.[7[ Pengertian lain sistem informasi dijelaskan yaitu sekumpulan komponen yang saling berhubungan untuk mengumpulkan atau mendapatkan, menyimpan, dan mendistribusikan informasi guna menunjang pengambilan keputusan dalam organisasi.[9] Ada definisi lain mengenai sistem informasi adalah cara yang terorganisasi untuk mengumpulkan, memasukkan dan memproses data dan menyimpannya, mengelola, mengontrol dan melaporkannya sehingga dapat mendukung perusahaan atau organisasi untuk mencapai tujuan. [5]

Sekumpulan halaman yang menampilkan informasi data teks, data gambar diam atau gerak, data animasi, suara, video dan atau gabungan dari semuanya, baik yang bersifat statis maupun dinamis yang membentuk satu rangkaian bangunan yang saling terkait dimana masing-masing dihubungkan dengan jaringan-jaringan halaman (hyperlink) disebut website.[11]

\section{Linkedin}

Menurut Wikipedia' Linkedin adalah sebuah bisnis layanan jaringan sosial dimana keuntungan penggunaannya bagi para professional yaitu membangun networking dan menciptakan brand di lingkungannya baik secara personal maupun group.

Secara spesifik keuntungan menggunakan Linekedin dapat dijelaskan seperti di bawah ini.

\section{a. Profesional Networking}

Linkedin dapat anda gunakan sebagai curriculum vitae (CV) anda yang dapat dilihat orang dari seluruh dunia. Fitur-fitur yang disediakan memudahkan anda untuk menulis detail diri dan pengalaman kerja anda. Hal ini pula yang membedakan LinkedIn dengan jejaring sosial lainnya.

b. Berhubungan dengan orang yang tepat.

Linkedin memiliki algoritma yang cerdas yang dapat menyarankan kepada anda orang-orang yang tepat sesuai dengan bidang anda dan juga grup-grup yang relevan dengan bidang pekerjaan anda. Dengan menjalin hubungan dengan orang-orang yang berada dalam bidang sejenis dengan anda, maka anda dapat memperluas jaringan kerja anda dan membuat orang lain sadar akan kemampuan anda. Selain itu anda juga dapat melirik profilnya untuk mempelajari lebih lanjut mengenai calon rekan anda.

c. Bergabung dengan grup yang tepat

Konsep grup di Linkedin jauh lebih baik dari pada Facebook yang sebagian besar merupakan sekedar grup lucu-lucuan. Grup dalam Linkedin merupakan hal yang berharga yang bisa anda ikuti. Semisal anda seorang pengusaha penjual handphone, maka anda dapat bergabung dalam grup sesama penjual handphone dan berdiskusi lebih lanjut dengan orang-orang yang ada di dalamnya.

d. Mencari Pekerjaan

e. Penelitian yang berjudul "Perancangan Sistem Informasi Data Alumni Fakultas Teknik Unsrat Berbasis Web". Penelitian ini menjelaskan tentang latar belakang dari sistem informasi data alumni yaitu pengolahan data masih manual. Adapun tujuan dari sistem ini yaitu untuk merancang suatu sistem informasi berbasis web. Perancangan sistem 
menggunakan metode waterfall yang terdiri dari tahapan System Information Engineering Requirements Analysis, Design, Coding, Testing, dan Maintenance. Pemodelan menggunakan Flowmap atau Flowchart, Diagram Konteks dan Data Flow Diagram. Dengan menggunakan metode Waterfall, dapat membantu dalam proses pembuatan aplikasi sistem informasi data alumni fakultas teknik UNSRAT.[3]

f. Penelitian yang berjudul "Sistem Informasi Berbasis Web. Untuk Membantu Kegiatan Tracer Study Program Diploma Institut Pertanian Bogor" Penelitian ini menjelaskan Program Diploma Institut Pertanian Bogor memiliki alumni yang tersebar di berbagai daerah di Indonesia. Program Diploma Institut Pertanian Bogor terus berusaha melakukan tracer study secara berkelanjutan setiap tahunnya. Cara yang dilakukan diantaranya adalah dengan menyebarkan kuisioner melalui pos, email, mailinglist, acara wisuda, pertemuan alumni, dan lain sebagainya. Selain itu, dilakukan wawancara dengan alumni secara langsung ataupun melalui telepon. Dengan melihat kegiatan Tracer Study Program Diploma IPB tersebut, Metode penelitian ini menggunakan metode pengembangan perangkat lunak model prototype. Sistem Informasi Tracer Study Program Diploma IPB memiliki fasilitas menampilkan laporan sehingga mempermudah dalam memperoleh informasi tentang alumni dan kepuasan pengguna. Informasi yang disajikan berupa tabel dan grafik. Selain itu, sistem ini juga dilengkapi fasilitas pencarian data alumni yang berfungsi untuk mempermudah pengguna mengetahui apakah alumni yang bersangkutan sudah turut serta dalam kegiatan tracer study.[2]Memang saat ini belum terkenal di Indonesia, namun beberapa perusahaan di Amerika sudah menggunakan Linkedin untuk mencari calon pekerja mereka. Hal ini dikarenakan fiturnya yang seolah-olah merupakan CV digital anda. Apabila anda membutuhkan karyawan, anda juga dapat mencarinya disini.

g. Membangun Brand Tren yang ada saat ini perusahaan baru dan lama membangun brand mereka melalui Facebook dan Twitter. Namun di Linkedin ada fitur yang lebih canggih karena anda bisa memasukkan nama brand anda disertai dengan statistikstatistik perkembangan perusahaan anda. Dan ini merupakan tutorial untuk membuat Linkedin di sini membuat account Linkedin.

\section{Literature Review}

Dalam literature review ini dimaksudkan untuk mengidentifikasi kesenjangan antar penelitian satu dengan penelitian lain, menghindari penelitian ulang, mengidentifikasi metode yang pernah dilakukan penelitian lain dan yang relevan dengan penelitian ini, dan meneruskan capaian penelitian sebelumnya, serta mengetahui kepakaran orang lain sehingga terjalin dalam komunitas yang sama. Hasil literature review dengan penelitian sebelumnya dapat diuraikan seperti-berikut:

1. Penelitian yang berjudul "Perancangan Sistem Informasi Penelusuran Data Alumni Berbasis Web". Penelitian ini menjelaskan pentingnya informasi yang berkaitan dengan penelusuran data alumni tersebut, namun masih banyak program studi di dalam perguruan tinggi baik swasta maupun negeri yang belum mengelola data tersebut secara baik. Kendala utama yang dialami dalam pengelolaan data tersebut adalah sulitnya menelusuri para alumni yang tersebar ke berbagai daerah setelah mereka lulus. Hal tersebut yang melatarbelakangi perlunya pengembangan sistem informasi penelusuran data alumni berbasis web. Metode pengumpulan data yang digunakan dalam menunjang penelitian ini adalah metode observasi dan interview dengan narasumber data yang relevan. Dengan mengembangkan system informasi berbasis web maka masalah penelusuran data alumni dapat teratasi karena alumni dapat 
memasukkan data perkembangan karir mereka dari manapun dan kapanpun mereka inginkan. Hal tersebut sangat membantu pengelola program studi dalam menelusuri alumni mereka dengan cara yang mudah dan sangat ekonomis.[12]

2. Penelitian yang berjudul "Rancangan Sistem Informasi Layanan Alumni ITENAS Berbasis Web". Meneliti tentang Fasilitas Layanan Alumni mengenai layanan lowongan pekerjaan secara online. Hal tersebut membuat alumni Itenas mengalami kesulitan dalam memperoleh informasi mengenai lowongan pekerjaan. Oleh karena itu, pada penelitian ini dirancang suatu sistem informasi berbasis website yang dapat memudahkan alumni Itenas dalam pencarian informasi mengenai lowongan kerja. Perancangan sistem informasi mengacu kepada kebutuhan-kebutuhan informasi yang diperlukan oleh pengguna, dan dimodelkan ke dalam diagram-diagram yang terdapat di dalam metode UML (Unified Modeling Language). Dengan adanya sistem ini, dapat dibuat sebuah website yang dapat menampung seluruh informasi mengenai alumni dan lowongan pekerjaan secara terpusat dengan cepat, tepat, dan akurat.[6]

3. Penelitian yang berjudul "Implementasi iMe (iLearning media) dalam mendukung system pembelajaran iLearning pada Perguruan Tinggi Raharja". Penelitian ini menjelaskan tentang suatu sistem pembelajaran yang berjalan pada Perguruan Tinggi Raharja, saat ini masih menggunakan kertas sebagai media pengerjaan tugas. Penggunaan kertas merupakan cara pembelajaran yang manual dan monoton. Sehingga kegiatan pembelajaran kurang menarik dan mahasiswa tidak dapat mengeksplor kreativitasnya dalam belajar. Untuk mendukung agar sistem pembelajaran dapat lebih menarik adalah dengan memanfaatkan teknologi informasi yang ada. iLearning adalah metode perkuliahan di Perguruan Tinggi Raharja yang menggunakan media iPad untuk mempermudah proses pembelajaran mahasiswa. Dengan adanya metode ini maka mahasiswa dapat belajar, bekerja, berdoa dan bermain dengan iPad. Istilah tersebut dikenal dengan nama 4B. iLearning Media atau disingkat dengan nama iMe adalah aplikasi berupa site yang dibuat dan dapat digunakan oleh seluruh mahasiswa Perguruan Tinggi Raharja untuk mengeksplor kreativitasnya dalam belajar. Ini merupakan sistem pembelajaran online yang memudahkan mahasiswa dalam belajar, karena dapat dilakukan di manapun dan kapanpun. Maka disimpulkan bahwa kontribusi iMe dapat dijadikan media informasi untuk sistem pembelajaran bagi seluruh civitas Perguruan Tinggi Raharja. Metode penelitian yang digunakan dalam melakukan penelitian ini adalah metode observasi dan studi pustaka. [8]

4. Penelitian yang berjudul "Perancangan Web Jejaring Sosial Penelusuran Alumni Sekolah Tinggi Teknologi Garut". Tujuan penelitian ini adalah perancangan web jejaring sosial penelusuran alumni Sekolah Tinggi Teknologi Garut. Perancangan sistem menggunakan Metodologi yang digunakan adalah Evolutionary Web Development (Ginige dan Murugessan, 2001). Hasil daripada penelitian ini adalah berupa rancangan sistem baru penelusuran alumni dengan berbagai fasilitas yang menunjang baik untuk kebutuhan kampus maupun untuk menunjang keubuthan alumni sendiri. Untuk menunjang kebutuhan kampus dirancangn fasilitas untuk mengolah dan menelusuri data alumni yakni fasilitas data member, fasilitas rekomendasi data alumni dan fasilitas report alumni. [1]

5. Penelitian yang berjudul "Sistem Informasi Alumni ITP menggunakan $P H P$ dan $M y S Q L$ ". Penelitian ini menjelaskan tentang pengelolaan database organisasi alumni ITP yang masih dilakukan secara manual, hal itu sering menyebabkan aktifitas organisasi menjadi terkendala. Organisasi ikatan alumni ITP merupakan organisasi 
yang menampung semua lulusan Istitut Teknologi Padang. Organisasi ini diciptakan bertujuan membantu akses komunikasi sesama lulusan Institut Teknologi Padang. Metodologi yang digunakan rancangan halaman utama menggunakan Entity Relationship Diagram .Tujuan dari penelitian ini adalah membangun dan mengimplementasi sistem informasi alumni ini dapat membantu mengatasi kendala yang selama ini di alami organisasi ikatan alumni ITP khususnya mengenai komunikasi dan pengolahan data, selain itu juga dapat bisa membantu operasional organisasi.Implementasi Sistem Informasi Alumni ITP ini dibangun menggunakan bahasa pemrograman $P H P$, database MySQL dan Apache web server.[13]

Hasil evaluasi dari kelima penelitian di atas dengan penelitian ini dapat disimpulkan bahwa penelitian ini mengembangkan penelitian sebelumnya dengan memanfaatkan web linkedin sebagai media social yang anggotanya para professional sehingga para anggota web alumni bisa saling sharing informasi dengan mereka.

\section{HASIL DAN PEMBAHASAN}

Setelah mengamati dan menganalisis dari beberapa permasalahan yang terjadi pada permasalahan yang ada, Peneliti mengusulkan beberapa alternatif pemecahan dari permasalahan yang dihadapi yaitu mengajak semaksimal mungkin kepada mahasiswa dan para alumni agar mau mempunyai akun linkedin dan melakukan activate pada web alumni.

Dan memberikan surat keputusan baik dari presdir dan direktur bahwa alumni yang baru lulus harus melakukan activate pada web alumni sehingga dengan ini para mahasiswa dan para alumni pasti akan mempunyai akun linkedin dan melakukan activate pada web alumni.

\section{Implementasi}

Untuk memudahkan dan mengetahui secara umum dan menyeluruh kandungan web alumniini dapat dilihat pada gambar 1 site map web alumni Perguruan Tinggi Raharja di bawah ini

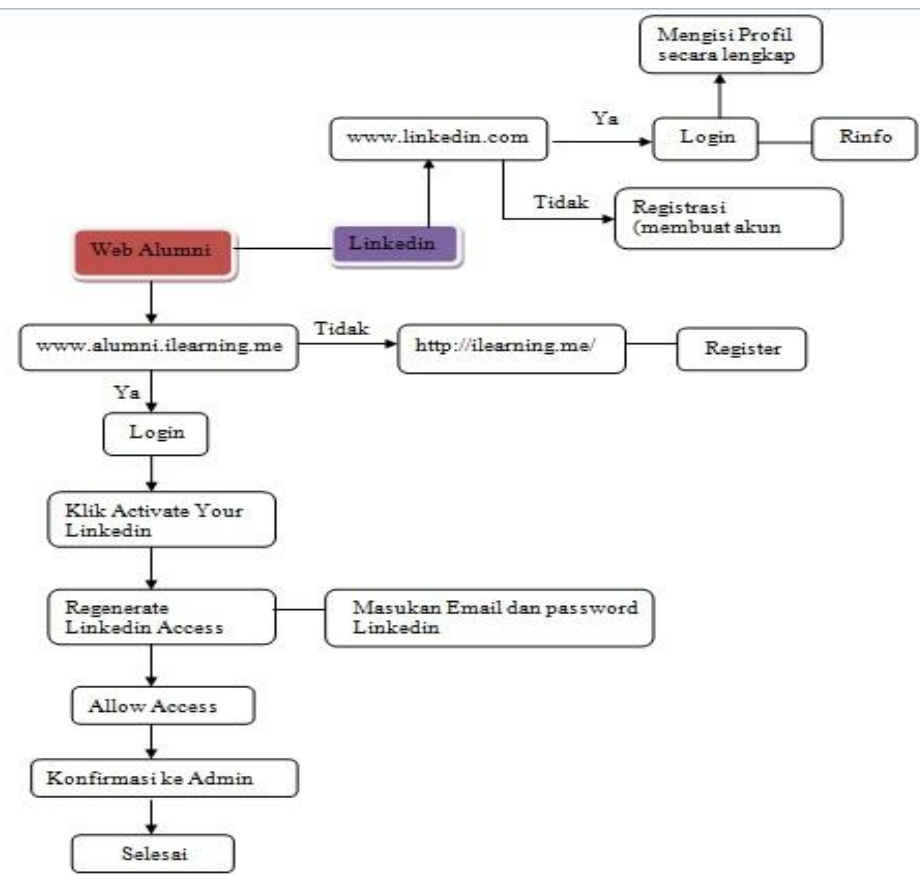

Gambar 1. Site Map Web Alumni Perguruan Tinggi Raharja 


\section{Tampilan Halaman Utama Web Alumni}

Pada tampilan halaman utama pada web alumni ini terdapat menu - menu yaitu ada menu home merupakan menu tampilan utama pada web alumni, menu tentang kami terdapat visi misi alumni perguruan tinggi dan logo alumni yang didalam nya terdapat mengenai filosofi logo, menu data alumni di dalam nya terdapat data mengenai alumni dan data persentasi jumlah alumni yang telah melakukan activate linkedin pada web alumni, menu gallery di dalam nya terdapat foto, video dan cerita mengenai alumni, menu activated your linkedin di dalam nya terdapat sebuah akses agar akun linkedin alumni dapat masuk kedalam web alumni, menu info loker (lowongan pekerjaan) di dalam nya terdapat informasi mengenai lowongan pekerjaan untuk para alumni nya, menu testimoni didalam nya terdapat sebuah pesan yang diberikan oleh alumni mengenai web alumni dan menu FAQ di dalam nya terdapat tutorial mengani cara cara untuk melakukan activate linkedin. Tampilan halaman utama web alumni ini dapat dilihat pada gambar 2 di bawah ini.

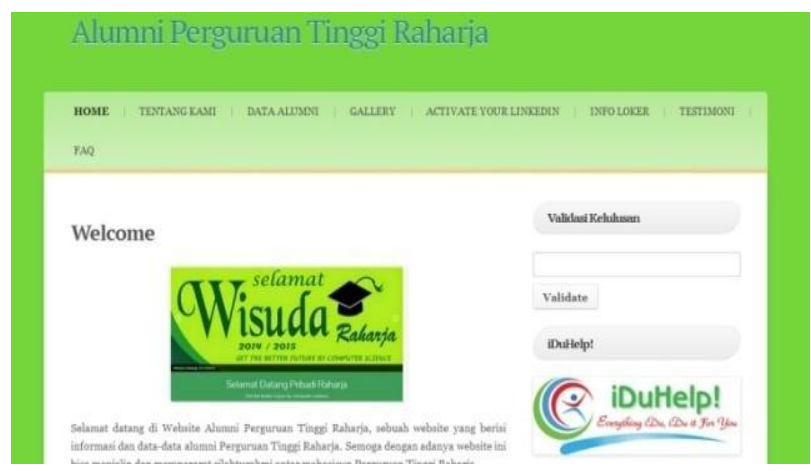

Gambar 2. Tampilan Halaman Utama pada Web Alumni

\section{Tampilan Menu Activate Your Linkedin}

Pada menu activate your linkedin digunakan untuk menghubungkan akun linkedin alumni dengan web alumni, agar akun yang berada pada linkedin bisa masuk kedalam web alumni. Di dalam menu activate your linkedin terdapat menu Regenerate Linkedin Access Token yang berfungsi untuk memasukan email dan password linkedin nya.

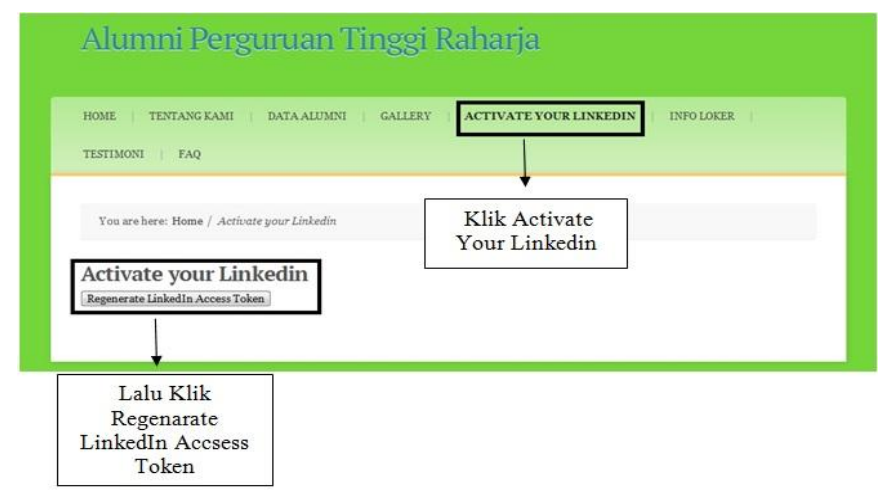

\section{Tampilan Menu Regenerate Linkedin Access Token}

Menu regenerate linkedin access token ini berisikan alamat email dan password linkedin anda dan pada Perguruan tinggi raharja harus menggunakan email rinfo, jika sudah mengisi email dan password linkedin anda maka silakan klik allow access agar email linkedin anda dapat masuk kedalam web alumni(lihat gambar 4). 


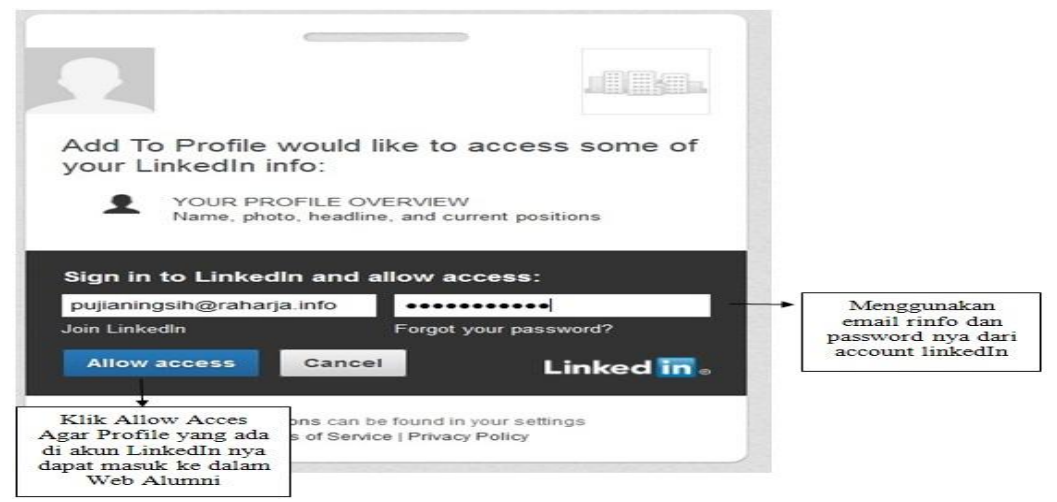

Gambar 4.Tampilan Menu Regenerate Linkedin Access Token

\section{Tampilan Mencari Nama pada Web Alumni}

Pada tampilan pencarian nama ini terdapat pada menu home yang di dalam nya terdapat menu validasi kelulusan yang digunakan untuk mencari nama alumni yang sudah melakukan activate linkedin (lihat gambar 5).

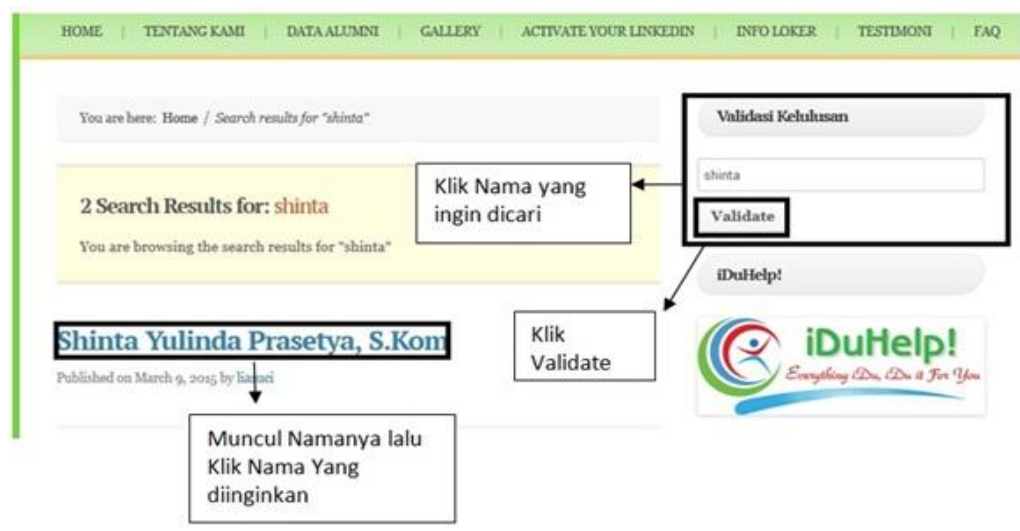

Gambar 5. Tampilan Mencari Nama pada Web Alumni

\section{Tampilan Profil Linkedin Pada Web Alumni}

Setelah mencari nama alumni dan alumni tersebut telah masuk ke dalam web alumni maka berikut ini merupakan tampilan yang terdapat pada alumni. Tampilan ini berasal dari profil yang terdapat pada akun linkedin alumni(lihat gambar 6).

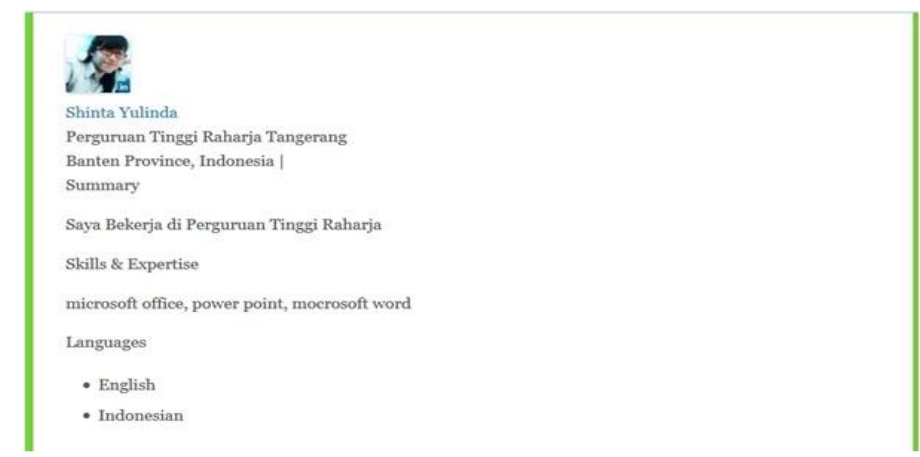

Gambar 6. Tampilan Profil Linkedin pada Web Alumni 


\section{Tampilan Halaman Utama Linkedin}

Pada tampilan halaman utama linkedin terdapat kolom yang harus diisi bila anda sudah mempunyai akun linkedin maka isi kolom pada bagian atas, jika belum mempunyai akun linkedin maka anda harus registrasi terlebih dahulu dengan mengisi kolom pada bagian bawah(lihat gambar7).

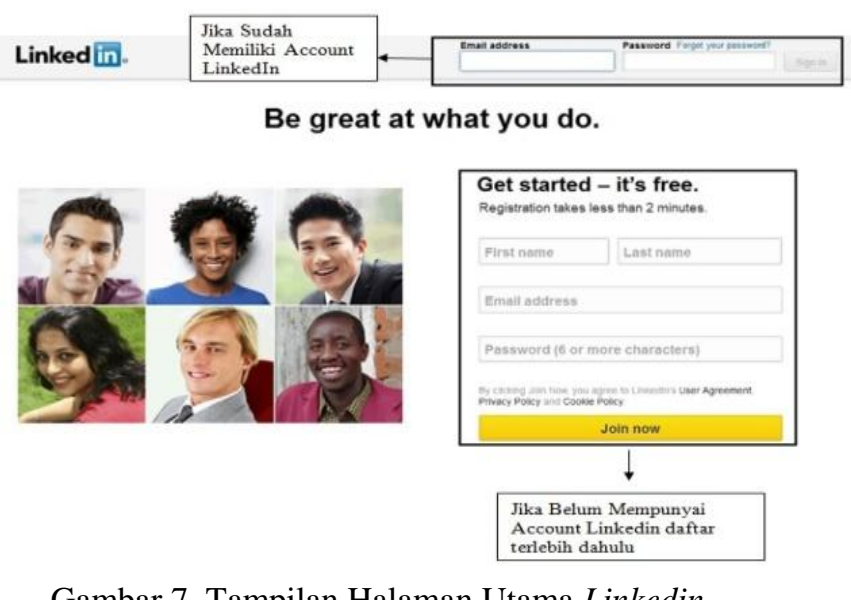

Gambar 7. Tampilan Halaman Utama Linkedin

\section{Tampilan Menu di dalam Linkedin}

Setelah login pada linkedin ini merupakan tampilan nya terdapat banyak menu didalamnya yang terdiri dari menu halaman utama merupakan halaman utama setelah anda melakukan login pada linkedin, menu profil didalamnya untuk melihat profil dan untuk mengedit profil, menu jaringan didalamnya itu untuk melihat kontak dan menambah kontak, menu pendidikan didalamnya digunakan untuk mencari universitas terbaik, menu pekerjaan didalamnya digunakan untuk mencari pekerjaan yang diinginkan, dan menu minat didalam nya terdapat update terbaru mengenai event-event pada grup yang ada dimana setiap menu nya memiliki fungsi nya masing-masing (lihat gambar 8).

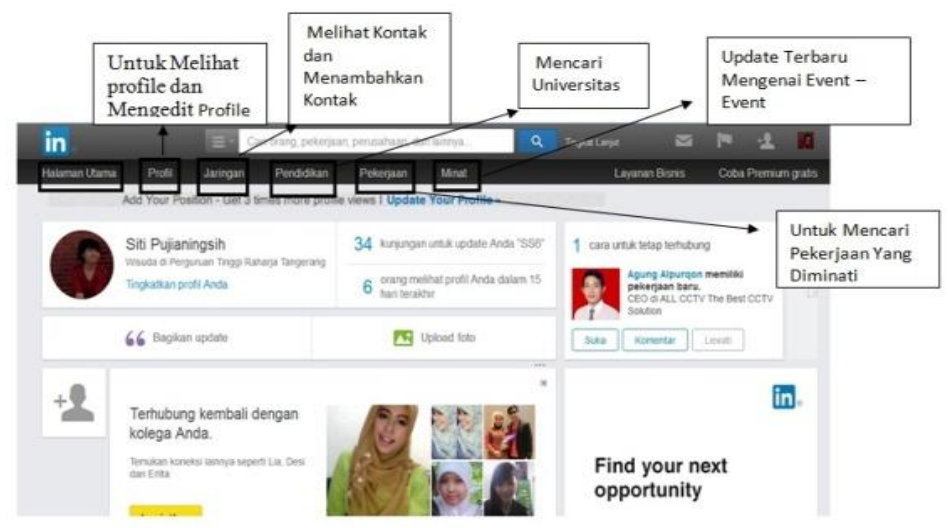

Gambar 8. Tampilan Menu di dalam Linkedin

\section{Tampilan Menu Pekerjaan pada Linkedin}

Ini merupakan tampilan pada menu pekerjaan yang apabila di klik maka akan muncul tampilan berikut ini. Dan di dalam nya terdapat banyak perusahaan yang bisa digunakan untuk melamar pekerjaan(lihat gambar 9). 


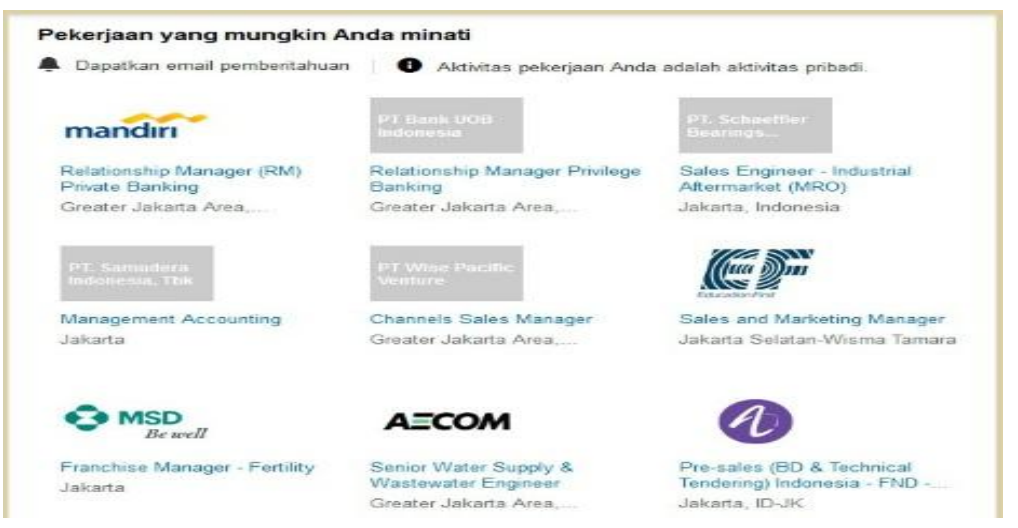

Gambar 9. Tampilan Menu Pekerjaan pada Linkedin

\section{Tampilan Profil Perusahaan Yang Dituju Pada Linkedin}

Bila sudah memilih perusahaan yang ingin dituju dan mengklik nya maka akan muncul tampilan seperti berikut dimana didalam terdapat menu lamaran sekarang, jumlah total yang sudah melamar dan deskripsi pekerjaannya (lihat gambar 10).

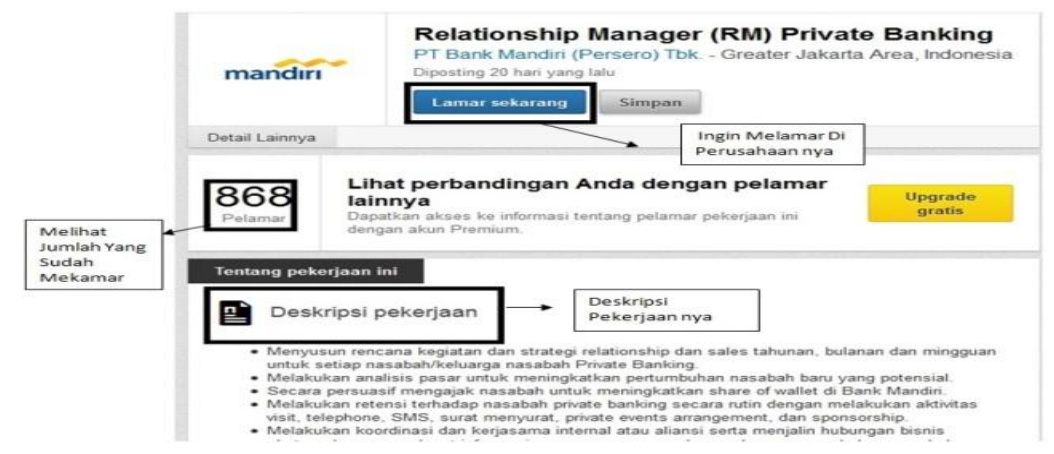

Gambar 10. Tampilan Profil Perusahaan Yang Dituju Pada Linkedin

\section{Tampilan Menu Lamaran pada Linkedin}

Menu lamaran yang terdapat pada linkedin merupakan lamaran yang langsung masuk pada profil anda jadi profil pada akun linkedin anda dapat di jadikan sebagai lamaran ke perusahaan yang dituju tinggal mengisi kolom dan nomor telepon anda yang dapat dihubungi lalu klik kirim yang nantinya profil linkedin anda akan ke kirim kepada perusahaan yang dituju(lihat gambar 11).

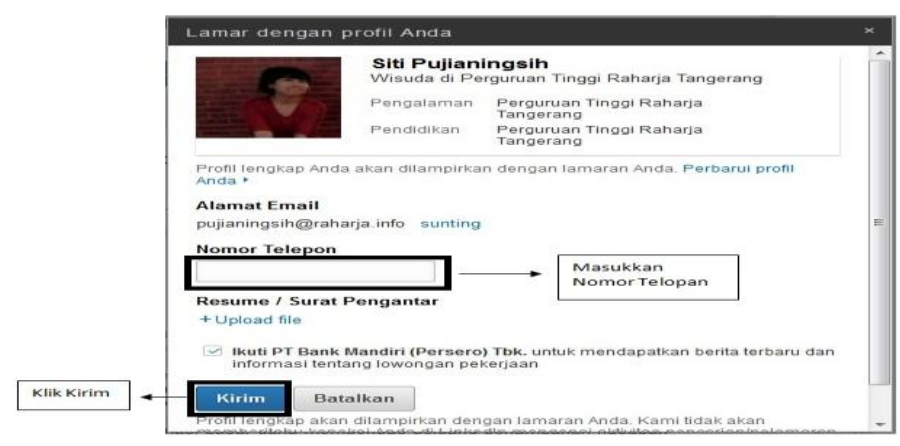

Gambar 11. Tampilan Menu Lamaran Pada Linkedin 


\section{Analisis Kelebihan dan Kekurangan Sistem}

Dalam penelitian ini disimpulkan bahwa sistem ini mempunyai kelebihan dan kekurangan yaitu:

Kelebihan pada sistem linkedin ini adalah mahasiswa raharja dapat melakukan activated pada web alumni karena apabila sudah melakukan activated pada web alumni, alumni diperbolehkan mengambil ijazah. Dan kelebihan yang lainnya adalah pada akun linkedin ini akan menjalin komunikasi sesama alumni, mahasiswa dan dosen, dan dengan mempunyai akun linkedin maka alumni dan mahasiswa akan dengan mudah untuk mendapatkan pekerjaan karena pada akun linkedin akan ada email masuk yang menawarkan pekerjaan.

Kekurangan pada sistem ini adalah linkedin ini merupakan media sosial yang masih baru dan hanya orang profesional saja yang memiliki akun nya. Pada sistem linkedin ini sudah sangat baik akan tetapi ada beberapa hal yang membuat para anggota linkedin merasa kebingungan dalam mengisi beberapa profil.

\section{KESIMPULAN}

Berdasarkan analisa yang telah diuraikan pada bab sebelumnya, maka dapat diambil kesimpulan tentang Pengembangan Web Alumni Dengan Menggunakan Linkedin Pada Perguruan Tinggi Raharja sebagai berikut :

Kondisi web alumni saat ini, digunakan untuk merekam data alumni baik yang sudah bekerja maupun yang belum bekerja. Jika beberapa alumni telah bekerja dan belum terekam ke database perguruan tinggi maka sulit untuk mendapatkan data terupdate.

Oleh karena itu dikembangkan web alumni dengan media social linkedin yaitu melakukan analisis system untuk mengetahui kelemahan dan kebutuhan system lebih lanjut. Hasil kelemahan system ini adalah media social linkedin ini merupakan media sosial baru untuk para professional sehingga kurang diminati masyarakat pada umumnya. Sedangkan keuntungan system ini memberikan informasi lowongan kerja, profil perusahaan yang menyediakan lowongan pekerjaa tersebut dan forum komunikasi antar anggotanya - alumni, dosen, mahasiswa, perusahaan, dan perguruan tinggi.

Selanjutnya system ini diimplementasikan dengan menyediakan fasilitas-fasilitas seperti regenerate linkedin access token, mencari nama-nama alumni, profil alumni, menu pekerjaan yang disediakan perusahaan dan profilnya serta lamaran kerja yang disertakan pada setiap profil alumni.

\section{DAFTAR PUSTAKA}

[1] Dani Ginanjar, Cepy Slamet, Erwin Gunadhi.2014. Perancangan Web Jejaring Sosial Penelusuran Alumni Sekolah Tinggi Teknologi Garut.. Garut: e-journal Sistem Informasi

[2] Indriasari, Sofiyanti .2012. Sistem Informasi Berbasis Web Untuk Membantu Kegiatan Tracer Study Program Dipoma Institut Pertanian Bogor.. Bogor: Jurnal Sains.

[3] Ivan Arifard Watung, Alicia A. E. Sinsuw, ST.,MT, Sary D. E. Paturusi, ST.,M.Eng, Xaverius B. N. Najoan, ST.,MT. 2014. Perancanagan Sistem Informasi Data Alumni Fakultas Teknik UNSRAT Berbasis Web.. Manado: e-journal Teknik Elektro dan Komputer 
[4] Jogiyanto.2003.Sistem Teknologi Informasi.Yogyakarta: Penerbit Andi.

[5] Laudon K.C. dan Laudon J.P , Graha Ilmu. 2014. Konsep Dasar Informasi. Hal 34.Yogyakarta: Yakub

[6] Muhammad Imam Alfarisyi, Rispianda, Khuria Amila. 2014. Rancangan Sistem Informasi Layanan Alumni ITENAS Berbasis Web.. Bandung: Jurnal Online Institut Teknologi Nasional.

[7] O’brian J.A, Graha Ilmu. 2014. Konsep Dasar Informasi. Hal 33.Yogyakarta: Yakub

[8] Rahardja, Untung. Sudaryono. Irwan Nurdin 2014. Implementasi iMe (iLearning Media)Dalam Mendukung Sistem Pembelajaran iLearning Pada Perguruan Tinggi. Tangerang: Jurnal CCIT Perguruan Tinggi Raharja.

[9] Rainer T.P, Graha Ilmu. 2014. Konsep Dasar Informasi. Hal 33.Yogyakarta: Yakub

[10] Robert A. Leitch, Graha Ilmu. 2014. Konsep Dasar Informasi. Hal 33. Yogyakarta: Yakub

[11] Serbatani, Analisis Website. 2013. Konsep Dasar Website. Hal 2.Jakarta: Serbatani

[12] Sutedi.2012. Perancangan Sistem InformasiPenelusuran Data Alumni Berbasis Web.. Bandar Lampung: Jurnal ilmiah Vol 6.

[13] Warman, Indra. Keni Novandri Saputra.2012. Sistem Informasi Alumni ITP Menggunakan PHP Dan My SQL..Padang: Jurnal Momentum Vol 12 No 1.

[14] Wikipedia.2014. Konsep Dasar Linkedin.Jakarta: Wikipedia 